\section{IMPACTO DE LA POLÍTICA DE REGULACIÓN DE MERCADO DE SUELO EN ECUADOR}

\author{
Victor H. Guaman ${ }^{1}$, Lorena Vivanco²
}

\section{Resumen}

La imperfección del mercado de suelo, precisa su regulación, ya que no se puede liberar al mercado esperando que el precio sea el equilibrio entre oferta y demanda. Este estudio determina el impacto de las políticas públicas orientadas a regular el mercado de suelo, a partir del análisis del precio del suelo en la ciudad de Cuenca, en base a tres criterios: incongruencia del valor de mercado con su valor de uso social; extracción de suelo urbanizado de la esfera de circulación; impacto de los excedentes especulativos en el acceso a la propiedad de suelo bien servido. Su aplicación evidencia que el recargo sobre los lotes ociosos no parece haber coadyuvado a la ocupación de las zonas centrales; por el contrario, los mayores valores de incremento de ocupación se registran en la periferia. Este

\section{IMPACT OF THE LAND MARKET REGULATION POLICY IN ECUADOR}

\author{
Victor H. Guaman, Lorena Vivanco
}

\section{Abstract}

The imperfection of the land market requires its regulation since the market cannot be freed while waiting for the price to be the balance between supply and demand. This study determines the impact of public policies oriented to regulate the land market, based on the analysis of land's price in the city of Cuenca using three criteria: market value inconsistent with its value for social use; urbanized land taken from the sphere of circulation; the impact of speculative surpluses from access to property of well-served land. Its application shows that the surcharge on idle lots does not seem to have contributed to the occupation of central areas, on the contrary, the highest values of increased occupancy are recorded in the periphery. This situation contributes to sprawling in the city, 
hecho contribuye a la expansión geográfica de una ciudad con bajos valores de densificación. Así, se evidencia que las valorizaciones se fundamentan en las rentas urbanas y no en la mejora de sus condiciones de valor de uso; de esta forma vemos como la ciudad muestra indicios de que el suelo periférico es igual de inaccesible que el central.

PALABRAS CLAVE: MERCADO DE SUELO, ESPECULACIÓN, SUELO URBANO, REGULACIÓN.

Recibido: 2019-06-22

Aceptado: 2020-04-22 with low densification values. It is evident that valuations are based on urban incomes and not on the improvement of their conditions of usevalue. The city of Cuenca shows signs that the peripheral soil is as inaccessible as the central one.

\section{KEYWORDS: LAND MARKET, SPECULATION, URBAN LAND, REGULATION.}

Received: 2019-06-22

Accepted: 2020-04-22

2 Universidad de Cuenca, Ecuador, http://orcid.org/0000-
0003-2286-3010. Correo electrónico: lorena.vivanco@
ucuenca.edu.ec 0002-1445-1430. Correo electrónico: vihguaman@gmail. com 


\section{Introducción}

El mercado de suelo urbano se entiende fundamentalmente como una instancia de intercambio de bienes inmuebles, en el que no solo se adquieren elementos tangibles como la tierra o edificaciones.

La "mercancía" en torno a la cual se desarrolla este mercado, es el suelo urbano. Éste es, por sí mismo, un bien escaso, y su relativa escasez se basa en su condición de bien no reproducible, lo cual depende de las determinantes de la regulación urbanística y de los propietarios del suelo (Espasa, Fittipaldi y Michalijos, 2010, p. 169). Por estas características no se puede liberar el mercado de suelo a la espera de que el precio sea el equilibrio entre de oferta y demanda (Acosta, 2019, p. 2; Martín y Camas, 2017).

La economía convencional sostiene que los precios del mercado inmobiliario libre reflejan el grado de coincidencia de la disposición y capacidad de pagar de un comprador con la de un vendedor; no obstante, este sistema no satisface necesidades sociales. Además, el mercado inmobiliario puede estar en movimiento constante, de modo que muchas familias, incluso aquellas fuera de la pobreza, no pueden acceder al mismo (Smolka, 2003). Las familias pobres, al no poseer un capital competitivo que afronte los valores fomentados por la especulación del suelo, son desplazadas hacia las afueras de la ciudad (Urriza, 2006, p. 145). El consecuente fenómeno espacial, denominado segregación, suma a la pobreza un efecto de diferenciación espacial, que conlleva una exclusión social más acentuada y una consecuente demanda de servicios en la periferia, que precisa que los gobiernos locales realicen fuertes inversiones (Cesare, 1998).

Latinoamérica es un laboratorio interesante para determinar hasta que punto el mercado de suelo se rige con las reglas ortodoxas del resto de los mercados. A partir de esto, la hipótesis de éste estudio sostiene que la expansión geográfica de las ciudades de Ecuador muestra indicios de que los procesos de comercialización del suelo se encuentran directamente relacionados con su configuración espacial. Ya que la subocupación gradual de suelo supone una mayor valorización en el suelo periférico, que lo vuelve inaccesible al igual que el suelo central, este fenómeno sería el resultado de débiles políticas públicas de regulación del mercado de suelo.

A partir de esta descripción, conviene preguntarse si los gobiernos municipales deben regular el mercado de suelo en Ecuador y por qué sus políticas han sido débiles para garantizar el acceso a la propiedad del suelo adecuadamente urbanizado, provocando que el suelo periférico sea igual de inaccesible que el central.

En este sentido, el presente artículo analiza el impacto de las políticas públicas orientadas a regular el mercado de suelo, a partir del 
estudio del precio del suelo en la ciudad de Cuenca, haciendo énfasis en aquellas políticas e instrumentos que el marco legislativo ecuatoriano concede a los gobiernos municipales.

\section{Problemática y estado del arte}

El costo elevado del suelo urbanizado en América Latina es uno de los rasgos imperantes en la persistencia del mercado de suelo denominado formal (Smolka, 2003). En éste, el "precio" se deriva de diversos factores asociados a las condiciones de accesibilidad, los cuales dependen: del transporte público y la infraestructura vial; de la proximidad a centralidades, y del nivel socio económico y las condiciones edilicias, entre otros (Baer y Kauw, 2016, p. 7). En el caso del mercado de suelo, en el intercambio no se paga únicamente por la adquisición de los derechos de propiedad sobre el mismo, sino que se lo hace fundamentalmente, por el derecho del acceso a la renta anticipada por la posesión del suelo (Gonzáles, 2016, p. 14). Por tanto, el valor que alcanza el precio del suelo responde a la presión de la demanda ante una mercancía escasa. Y los réditos se materializan en el incremento del precio del suelo con el paso del tiempo y las operaciones inmobiliarias.
Para Jaramillo, Moncayo y Alfonso (2011), existen tres tipos de movimientos del precio del suelo urbano, que están asociados a diversas determinantes económicas. Esta investigación se centra únicamente en los movimientos estructurales particulares», pues están relacionados a la gestión del suelo por parte de los gobiernos locales y evidencian valorizaciones excesivas por el estímulo del Estado, debido a la inversión en infraestructura, el cambio de uso del suelo o el solo anuncio de un proyecto. Por ejemplo, en Barra da Tijuca (Río de Janeiro, Brasil) el anuncio de proyectos viales generó incrementos del valor del suelo en un 1900\% entre 1972-1975 (Smolka, 2014, p. 5). En otros casos, el cambio de uso rural a urbano genera un alza de entre cinco y diez veces su valor, incrementos que están aún por encima de los costos que conlleva la urbanización.

En los incrementos de valor del suelo propiciado por este factor de cambio de usos, se identifica el «multiplicador urbano», entendido como "la relación entre el precio por metro cuadrado de la tierra designada para usos urbanos con su valor anterior de usos rural (agrícola) en el borde urbano" (Smolka, 2014, p. 6). En Latinoamérica, es un fenómeno común identificar este valor en relaciones de 4:1. Por ejemplo, en Río de Janeiro (Brasil) se evidenció un multiplicador de seis veces el valor de la tierra rural y en Quito (Ecuador), el multiplicador se calculó en 5:1 (Smolka, 2014, p. 6). 
En experiencias más recientes (2004-2014), se identifica el caso del corredor metropolitano sur de Buenos Aires, que experimentó una valorización anual del $17,7 \%$, en tanto que los corredores del oeste y norte, lo hicieron en un 10,4 y $8,9 \%$ respectivamente. La considerable diferencia en la valorización, se debió a la influencia del trazado ferroviario en el corredor sur (Baer y Kauw, 2016, p. 12). En el caso de Bogotá, entre 1970 y 2012, el precio del suelo evidenció un incremento del 4,4\% anual en zonas de estrato de altos ingresos, mientras que para los estratos bajos lo hizo en un 2,41\%. En este fenómeno incidió preponderantemente el incremento de la densidad edificatoria (Jaramillo, 2014, p. 25), aspecto regulado por los gobiernos locales mediante la normativa urbanística.

Lo anterior muestra que los incrementos en el precio del suelo, si bien surgen por estímulos en la mejora de sus características que permiten el adecuado desarrollo de los usos urbanos, no se ven sustentados en el costo de las inversiones, sino que se les aduce un excedente apoyado en las rentas urbanas, pues se mejoran así las condiciones edilicias, de conectividad y usos siendo éstos los factores que condicionan mejores plataformas para las rentas como la de comercio. A esta diferencia entre los costos de producción de dicho suelo y el valor de mercado se le denomina plusvalía, pues son aumentos de precio que no son respaldados por un real incremento del valor de uso social del suelo. En base a este fenómeno económico se producen intercambios inequivalentes, de los cuales pretende lucrarse el capitalista, que llamaremos prácticas especulativas urbanas.

Los excedentes especulativos que alcanza el suelo se deben, según la experiencia teórica, a la imperfección de su mercado. Y entre algunas particularidades que condicionan su deficiente funcionamiento están:

- La espiral inflacionista: el incremento de la demanda se ve respaldada por una excesiva financiación con incipiente control sobre los préstamos hipotecarios.

- Racionalidades de los agentes: proliferación de prácticas especulativas como la retención del suelo en la espera de valorizaciones, para optimizar los rendimientos del capital.

- Heterogeneidad del suelo: el precio se construirá sobre sus características particulares, siendo una de las principales, su localización.

- La asimetría en la información: las personas que adquieren suelo no cuentan con información suficiente sobre las características del bien y de su precio, lo que deriva en ineficiencias en el proceso de la toma de decisiones 
- La elasticidad de la oferta y la demanda: al no existir bienes sustitutivos, la escasez del bien provoca la subida de precios, (Martín y Camas, 2017, p. 5-14).

El espacio urbano presenta una diversidad de externalidades, que determinan al suelo como una mercancía heterogénea. Es decir, tiene una limitada «amplitud», que se define como "el grado en que los bienes sujetos a intercambio pueden sustituirse unos por otros" (Martín y Camas, 2017, p. 7). Ello implica el agravio de la inelasticidad de la oferta y la demanda de este mercado, ya que en un principio existe escasez física de suelo, a lo que se le suma un fenómeno de escasez jurídica (regulación urbanística). Se presenta también, un fenómeno de «escasez económica» que se refiere a agentes que retiran suelo del mercado.

Ante la existencia de un mercado con fallos que gira en torno a una mercancía con particularidades que lo hacen monopolizable (por ser el suelo un bien de consumo obligatorio), los excedentes especulativos en el precio del mercado formal de suelo hacen que el mercado informal sea el principal medio de acceso a la ciudad para la mayoría de la población (Camargo y Hurtado, 2013, p. 104). Por tanto, es imperante evaluar el impacto de las políticas públicas orientadas a su regulación, de modo que mediante su ratificación o rectificación se propenda a garantizar el derecho a la ciudad. Si bien muchos países generan instrumentos y políticas para controlar este mercado, aún se está lejos de erradicar sus imperfecciones, pues sus medidas contribuyen a distorsionar más aún estas operaciones.

La ausencia de regulación y la exención tributaria de los plusvalores que son generados con esfuerzo social a través del Estado impiden la distribución equitativa de las rentas y riqueza, favoreciendo a los propietarios oportunamente ubicados. Si bien cada lote es un bien privado, es también uno público, por ser un emisor y receptor de externalidades. Entonces, el manejo del suelo urbano debe ser sujeto de un cúmulo de herramientas jurídicas y económicas que coadyuven a satisfacer fines de justicia social, conservación del medio ambiente y eficiencia económica (Urriza, 2006, p. 159).

La participación del Estado, a través de las políticas públicas, debe orientarse al objeto de garantizar las condiciones necesarias para un equitativo acceso al suelo urbano, para así efectivizar la materialización del derecho a la ciudad. Para ello, la generación y aplicación de instrumentos de promoción de hábitat popular (impuestos redistributivos al suelo, movilización de plusvalías, entre otros) permite incidir de manera efectiva en el mercado de suelo (Bagnera, 2016, p. 10). En este camino, se ha evidenciado que diferentes formas de regulación del mercado de suelo urbano han contribuido al acceso a la ciudad formal para los sectores económicamente vulnerables, a través de la promoción de viviendas de interés social en zonas adecuadamente urbanizadas. Un claro 
ejemplo es el de California, donde, entre 1999 y 2003, se edificaron 1400 viviendas sociales en 88 desarrollos, a través de la utilización de los denominados bonos de densidad (Molinatti, 2013, p. 140). Este tipo de estrategias permitió que las familias con bajos ingresos se integraran a algunos de los barrios más caros de la zona. En el caso de la ciudad de Sao Paulo, Brasil, el impulso del proyecto "Mi casa mi vida", produjo que se desarrollaran más programas de VIS de iniciativa privada, en sectores declarados como Zonas Especiales de Interés Social; esto, debido a que, aunque existían los incentivos para la creación de programas de vivienda social en estas áreas, se ejecutaban más programas de iniciativa pública que privada.

En Ecuador, el derecho a la ciudad como precepto constitucional, determina que "las personas tienen derecho a un hábitat seguro y saludable, y a una vivienda digna y adecuada, con independencia de su situación social y económica", (Const., 2008, art. 30); y es el Estado el que garantiza en todos sus niveles de gobierno el derecho a la vivienda.

Corresponde entonces, a los gobiernos municipales y metropolitanos la competencia exclusiva de regular el uso y la ocupación del suelo, de vigilar y controlar "la obtención de beneficios a partir de prácticas especulativas sobre el uso del suelo, en particular por el cambio de uso, de rústico a urbano o de público a privado" (Const., 2008, art. 376), y de garantizar el derecho al suelo urbano y la regulación del mercado de suelo (Figura 1).

Estapolíticanacional,seratificaenlaLeyorgánica de ordenamiento territorial, uso y gestión de suelo, cuando dentro de las implicaciones de la función social y ambiental de la propiedad, se antepone el interés general sobre el particular, garantizando así, nuevamente, "el control de prácticas especulativas sobre bienes inmuebles" (Ley orgánica de ordenamiento territorial, uso y gestión de suelo, 2016, art. 7, numeral 5).

La Ley orgánica de ordenamiento territorial, uso y gestión de suelo desarrolla los «instrumentos para regular el mercado de suelo», que son "mecanismos útiles para evitar prácticas especulativas sobre los bienes inmuebles y facilitar la adquisición de suelo público para el desarrollo de actuaciones urbanísticas, (Ley orgánica de ordenamiento territorial, uso y gestión de suelo, art. 60). Algunos procesos que se rigen en torno a la aplicación de estos instrumentos se basan en: la declaración de zonas urbanizables con consecuentes enajenaciones forzosas -movilización de suelo; delimitación de zonas especiales de interés social; expropiación de suelo con costos por debajo del valor comercial; oferta de suelo con análisis de capacidad de pago, etc. Estos son mecanismos de regulación del mercado de suelo que permiten vivienda social en suelo urbano bien ubicado, la que en condiciones normales de mercado no sería posible (Acosta, 2019, p. 3). 
FIGURA 1. INSTRUMENTOS LEGISLATIVOS RELACIONADOS LA GESTIÓN DEL SUELO EN ECUADOR.

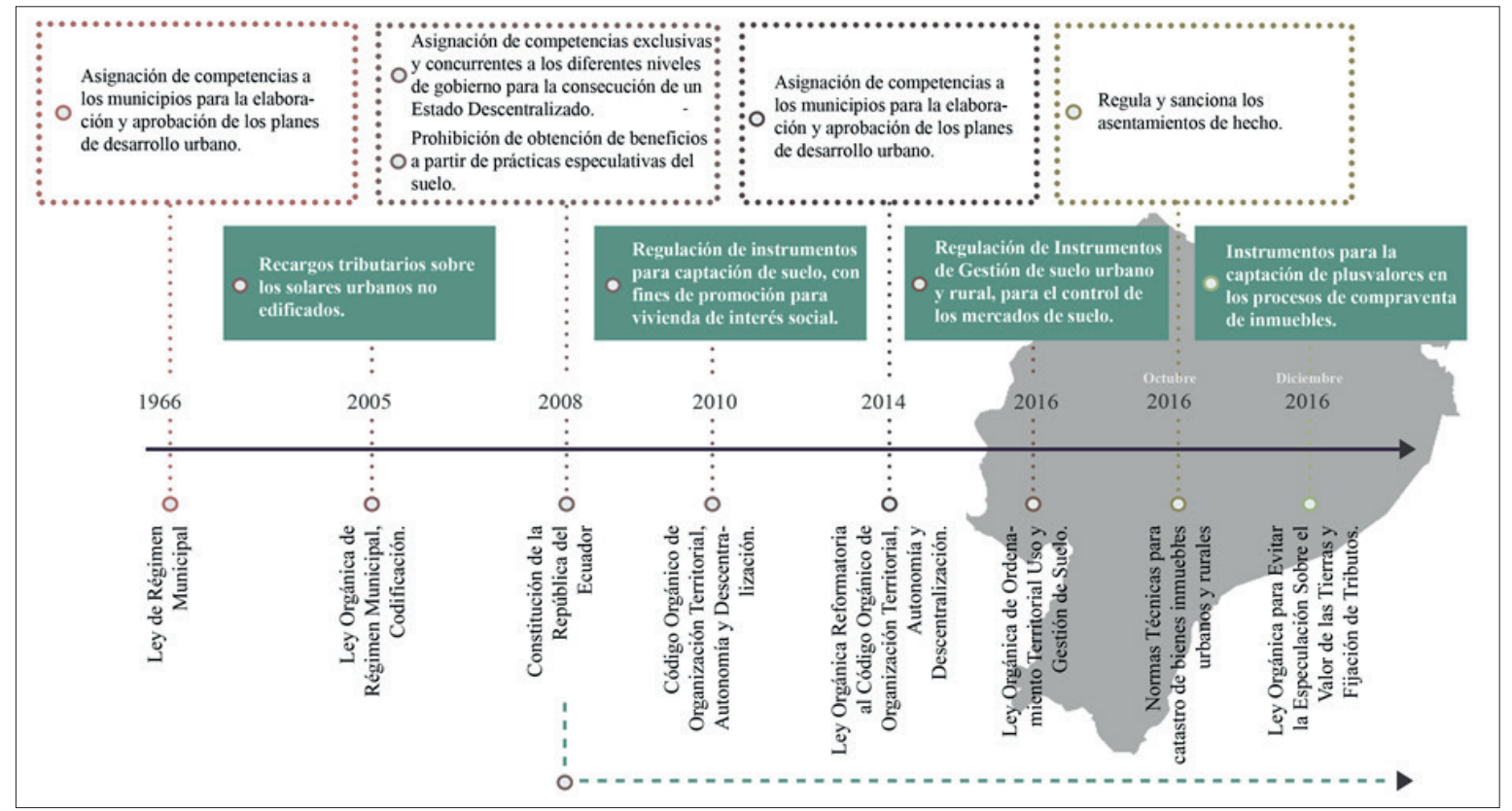

Fuente: Autores, 2019. 
Otras herramientas, que se erigen en torno a la regulación del mercado son aquellas orientadas a la captura de plusvalías. Por ejemplo: el Impuesto a las utilidades y Plusvalía, que consiste en un impuesto aplicado a la transferencia de inmuebles urbanos (Código orgánico de organización territorial, autonomía y descentralización, 2010, art. 556); la Contribución Especial de Mejoras, consiste en el pago a los municipios por el "beneficio real o presuntivo proporcionado a las propiedades inmuebles urbanas por la construcción de cualquier obra pública" (Código orgánico de organización territorial, autonomía y descentralización, 2010, art. 569); el Impuesto a los Predios Urbanos (un impuesto a la tenencia que se define por el valor catastral de la propiedad). Otro aspecto en materia de regulación del mercado es el recargo para los lotes ociosos (Código orgánico de organización territorial, autonomía y descentralización, 2010, arts. 507 y 508), introduciendo estos lotes a la esfera de circulación, para reducir las valorizaciones soportadas en la renta absoluta urbana.

Sin embargo, el instrumento que más incidencia tendría en la captura de plusvalías y la regulación del mercado de suelo en Ecuador es la Ley orgánica para evitar la especulación sobre el valor de las tierras y fijación de tributo (2016) (actualmente derogada). Dicha ley, conocida también como Ley de Plusvalías, consistía en la participación de los gobiernos locales en las denominadas ganancias extraordinarias de los intercambios de bienes inmuebles, la cual según el artículo 561.10, es "la diferencia entre el valor de transferencia del bien Inmueble y el de adquisición ajustado", donde el valor de adquisición ajustado, es el de la suma de adquisición más la ganancia ordinaria, que se define como el valor de adquisición del bien inmueble multiplicado por un factor de ajuste, mismo que era el resultado de un promedio de la tasa de interés pasiva referencial para depósitos a plazo de 361 días y más.

Esta ley tenía por objeto propiciar la trasferencia de bienes inmuebles con exención de valores especulativos, desincentivando la mercantilización indiscriminada del suelo y la captura y redistribución de las rentas, pues, según el artículo 561, los valores recolectados se debían destinar "a la construcción de vivienda de interés social y prioritario". No obstante, la confluencia de la expedición de la ley con un ciclo económico en recesión para el sector de la construcción -que venía desde el 2014constituyó un fuerte argumento manejado por los "perjudicados" para forzar su derogatoria en febrero de 2018, a través de una consulta popular.

En síntesis, el Estado ecuatoriano cuenta con algunas políticas públicas e instrumentos que le permiten interferir en el mercado de suelo y con ello coadyuvar a la inclusión de todas las personas en el mercado formal de suelo y garantizar el derecho a la ciudad. Esto 
implica que los gobiernos locales propicien y construyan ciudades inclusivas a través de la aplicación dichos instrumentos; esto, al generar controversia, termina por comprometer su capital político, resultando en la prescindencia del uso de estas políticas públicas. Su dificultad radica en la escasa captación tributaria, debido a la posesión de catastros desactualizados y con avalúos que no alcanzan el valor de mercado, lo cual, junto a otros aspectos, impide financiar programas de vivienda social.

\section{Metodología}

El análisis del precio del suelo comienza por identificar algunos factores que se constituyen y derivan de las prácticas especulativas. Éstos son: valor de mercado incongruente con su valor de uso social; extracción de suelo urbanizado de la esfera de circulación; impacto de los excedentes especulativos en el acceso a la propiedad de suelo bien servido. Identificadas estas variables que provienen de registros originales, se procesan los datos para la ciudad de Cuenca de acuerdo a la normativa legal vigente, en base al salario básico unificado y las edificaciones en el área urbana, tal como se detalla en la Tabla 1.

\section{Las fuentes del precio del suelo urbano en Ecuador}

El área de estudio seleccionada, «Cuenca», es una ciudad patrimonio cultural de la humanidad, una ciudad intermedia y una ciudad región, con un predominio de la actividad manufacturera, de construcción, de comercio y de las actividades profesionales e inmobiliarias, que concentraron el 60\% del valor agregado bruto del cantón (BCE, 2017). Su aporte al PIB en la provincia del Azuay asciende al 97\%. Estos aspectos condicionan la presencia de diversas modalidades de la renta, que son la base de los valores especulativos.

Para el análisis de las fuentes de información, se han considerado los registros originales ${ }^{3}$ como: el plano del valor de la tierra ${ }^{4}$ (que es un plano que grafica la fijación de valores catastrales por metro cuadrado, clasificándolo en zonas geoeconómicas homogéneas, cuyo cálculo se realiza mediante un proceso de comparación de valores de mercado) y el plano de precios basado en la cuantía de los bienes inmuebles, que trata del valor que se inscribe en la escritura pública, en los procesos compraventa. Cabe recalcar que el valor inscrito en la cuantía no necesariamente refleja el monto real del intercambio.

3 Implica que un dato está certificado y que la entidad competente es la responsable de producir, actualizar y mantener el dato.

4 Generado por los gobiernos locales por disposición del Código orgánico de organización territorial, autonomía y descentralización (2010). 
TABLA 1. INFORMACIÓN GENERADA POR DISPOSICIÓN DE UNA NORMATIVA LEGISLATIVA.

\begin{tabular}{|c|c|c|c|c|c|}
\hline \multicolumn{2}{|l|}{ Normativa } & Fuente & Periodicidad & Disponibilidad & Observaciones \\
\hline \multirow{2}{*}{$\begin{array}{l}\text { Edificaciones } \\
\text { en el área } \\
\text { urbana }\end{array}$} & $\begin{array}{l}\text { Ley orgánica de } \\
\text { régimen municipal, } \\
\text { codificación, 2005, } \\
\text { arts. } 153,306 \text { y } \\
308 .\end{array}$ & $\begin{array}{l}\text { Sistema de catastro urbano, } \\
\text { en donde constan los } \\
\text { bienes inmuebles en el } \\
\text { catastro que deben ser } \\
\text { actualizados cada bienio, } \\
\text { por el GAD municipal o } \\
\text { metropolitano. }\end{array}$ & Bienal & Nacional & \multirow{2}{*}{$\begin{array}{l}\text { El registro de los } \\
\text { bienes inmuebles } \\
\text { y su actualización } \\
\text { bienal precisa } \\
\text { que los gobiernos } \\
\text { locales cuenten } \\
\text { con un registro } \\
\text { georreferenciado } \\
\text { de las } \\
\text { edificaciones } \\
\text { desde el año } \\
2006 \text { en adelante. }\end{array}$} \\
\hline & $\begin{array}{l}\text { Código orgánico } \\
\text { de organización } \\
\text { territorial, } \\
\text { autonomía y } \\
\text { descentralización, } \\
2010 \text {, arts. } 139 \text { y } \\
494 .\end{array}$ & $\begin{array}{l}\text { Determinan la } \\
\text { obligatoriedad de la } \\
\text { constatación de los bienes } \\
\text { inmuebles en el catastro, } \\
\text { así como la obligatoriedad } \\
\text { de actualización cada dos } \\
\text { años. }\end{array}$ & Bienal & Nacional & \\
\hline \multirow[t]{2}{*}{$\begin{array}{l}\text { Salario Básico } \\
\text { Unificado }\end{array}$} & $\begin{array}{l}\text { Código del trabajo } \\
\text { codificación, } 2005 \text {, } \\
\text { art. } 117 \text {. }\end{array}$ & $\begin{array}{l}\text { El Estado, a través del } \\
\text { Consejo Nacional de } \\
\text { Trabajo y Salarios -CNTS- } \\
\text {, establece anualmente } \\
\text { el sueldo o salario } \\
\text { básico unificado para los } \\
\text { trabajadores privados. }\end{array}$ & Anual & Nacional & \multirow[t]{2}{*}{$\begin{array}{l}\text { Existe un registro } \\
\text { elaborado por } \\
\text { el CNTS, del } \\
\text { Salario Básico } \\
\text { Unificado con } \\
\text { una periodicidad } \\
\text { anual desde el } \\
\text { año } 2005 \text {. }\end{array}$} \\
\hline & $\begin{array}{l}\text { Const., 2008, art. } \\
328 .\end{array}$ & $\begin{array}{l}\text { El Estado fija y revisa } \\
\text { anualmente el salario } \\
\text { básico establecido en la } \\
\text { ley, de aplicación general y } \\
\text { obligatoria. }\end{array}$ & Anual & Nacional & \\
\hline
\end{tabular}

Fuente: Autores, 2019. 
Por otro lado, se recopiló información no oficial, correspondiente a la oferta de bienes inmuebles, disponible en medios de comunicación escrita de la localidad. El resultado son 413 puntos georreferenciados que representan el precio por metro cuadrado, donde el 15,73\% constituye el precio real de las transacciones conseguido mediante contacto telefónico con el vendedor, y el $84,27 \%$ corresponde a la oferta publicada. Para la construcción del plano de precios de la oferta y del plano de precios basado en la cuantía, se ha utilizado la misma delimitación cartográfica de las zonas geonómicas homogéneas que usa el plano del valor de la tierra. Además, se calculó la media del precio con un coeficiente de variabilidad del $15 \%$. Ello ha condicionado que el cálculo del precio se haga únicamente para algunas zonas, ya que en algunos casos no se contó con las suficientes referencias y en otros se presenta una excesiva dispersión en los datos.

El período de recopilación de los datos -2016 a 2017- tiene correspondencia con la derogada Ley de Plusvalías y su incidencia en el movimiento del precio del suelo. La siguiente figura, presenta la media del precio del suelo en algunas zonas, proveniente de las fuentes mencionadas.

En la Figura 2, se observa que en el 75\% de las zonas presentadas los valores de la cuantía son similares al plano del valor de la tierra. En zonas como la S-6 y E-8, el precio declarado por cuantía evidencia un incremento de más del $100 \%$ para el 2017. Esto se da, posiblemente, con la intención de reducir la diferencia de valores declarados con la futura venta, y así quedar exento de la ganancia extraordinaria (Ley de Plusvalías). En la zona N-17 se presentan, en 2017, nueve procesos de compraventa donde se declara un valor promedio de $792 \$ / \mathrm{m}^{2}$. Dicha cantidad supera en un $1266 \%$ al precio establecido en el plano del valor de la tierra para esta zona.

La declaración de valores de compraventa por debajo del valor de mercado implica una baja tributación al Servicio de Rentas Internas, y un reducido pago por concepto de alcabalas y plusvalía, lo cual deriva en reducidos valores de recaudación para los gobiernos locales. No obstante, se evidencia la potencialidad que tenía la Ley de Plusvalías en la mejora de la tributación.

La Figura 2, muestra que para el año 2016 el avalúo municipal está por debajo del $60 \%$ del valor de la oferta en el 54,54\% de las zonas; para el 2017, en el 48,48\%. Fenómeno común en Ecuador, ya que el avaluó municipal está por debajo del $50 \%$ del valor de mercado en el área urbana (Reyes y Tubío, 2018), aspecto que deviene en una baja recaudación del impuesto predial. Por lo tanto, se corroborará que para un adecuado análisis del precio del suelo, es imperante el uso de la información proveniente de la oferta. 
FIGURA 2. PRECIOS DEL SUELO URBANO EN CUENCA.
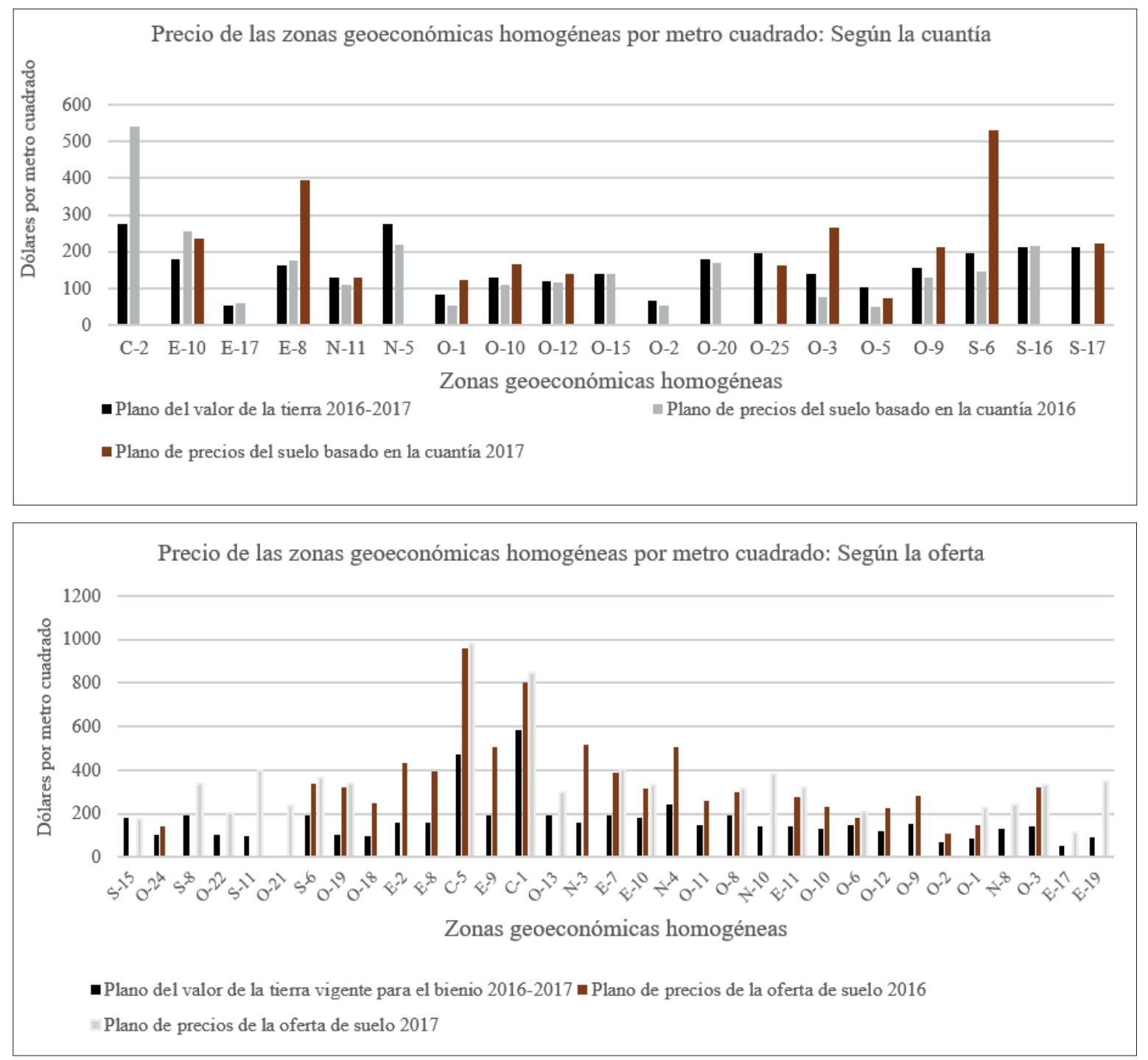

Fuente: elaboración propia. 
Luego, a partir de un análisis cuantitativo del precio del suelo urbano, se concreta el planteamiento de los indicadores que se describen a continuación:

a. Valor de mercado incongruente con su valor de uso social

El valor social del trabajo implica la suma de los costos de producción y el trabajo-tiempo invertido en una mercancía, no obstante, en este valor y su materialización -que es el precio de mercado- existe una divergencia cuantitativa y cualitativa (Harvey, 2014, p. 46). En el caso del suelo urbano, su valor está constituido por factores asociados a su localización, además de la disponibilidad de servicios básicos ${ }^{5}$, o sea, aquellos que fomentan el adecuado desarrollo de los usos urbanos (que tienen como centro la vivienda). El indicador permite contrastar el porcentaje de disponibilidad de estos servicios (que constituyen un valor de uso social) en una zona, con su precio en el mercado.

Indicador: Relación precio suelo Infraestructura urbana

b. Extracción de suelo urbanizado de la esfera de circulación

5 Agua potable, alcantarillado, recolección de desechos sólidos, energía eléctrica, telefonía fija.
Una de las prácticas especulativas que contribuye a la proliferación de las rentas urbanas, puntualmente a la renta absoluta urbana, es la retención de suelo urbanizado. Este indicador permite establecer una relación en el tiempo, entre el espacio edificable total y el edificado en el área urbana.

\section{Indicador: Porcentaje de suelo urbano edificado}

c. Impacto de los excedentes especulativos en el acceso a la propiedad de suelo bien servido

Se precisa identificar un factor que evidencie el crecimiento del precio de otras mercancías, con el objeto de que su incremento se pueda comparar con el del precio del suelo urbano. El precio de otras mercancías se refleja en el Índice de Precios al Consumidor (IPC), que es el referente para la cuantificación del proceso inflacionario. Si se tiene presente que la fijación del Salario Básico Unificado (SBU), tienen como referente principal a la inflación, la comparación del SBU con el precio del suelo mediante este indicador nos permite: exponer la cantidad de recursos en el SBU que se requiere para acceder al suelo urbano cada año y entender la diferenciación del incremento del precio del suelo con el de otras mercancías. 
Indicador: Relación precio suelo - Salario Básico Unificado

Para la aplicación de los indicadores ${ }^{6}$ en la ciudad de Cuenca, se han establecido previamente las zonas de estudio en las cuales habrían incidido los factores de incremento del precio del suelo urbano asociados a la gestión del suelo y que, además, cuentan con información referente al precio proveniente de la oferta entre el 2016 y 2017. Su delimitación espacial se basa en los límites cartográficos de los sectores de planeamiento de la ciudad y se complementa con la incorporación de variables asociadas a las condiciones urbanísticas, como las determinantes de uso y ocupación del suelo que, establecidas mediante la normativa, definen su "fertilidad" -es decir el aprovechamiento edificatorio del suelo.

\section{Resultados}

a) En relación al valor de mercado incongruente con su valor de uso social

En la Figura 3, se puede observar que el precio del suelo presenta una valorización gradual en torno a su distancia al centro, sin embargo, el incremento es diferenciado en las distintas zonas homogéneas. En 2016 y 2017 la media del precio de la zona E-31 es mayor al de las zonas O-9 y O-23, pese que su distancia al centro es el doble que el de estas últimas. Con el supuesto de que los atributos propios del suelo urbano (servicios básicos) son los que constituyan el factor preponderante en la composición del mayor precio del E-31, se explora el indicador relación precio suelo- infraestructura urbana.

Contrario a lo que se puede pensar, la Figura 4 pone en evidencia que la zona E-31 presenta el mayor valor del indicador, aun por sobre el sector central. Si bien el precio de la E-31 es el 36,58\% del exhibido en el área central, su porcentaje del IASPB, es el menor (27\%). Bajo la lógica de este indicador, el precio no justifica su valor, menos aun debido a la distancia al centro. Por otra parte, la zona E-7 muestra el menor valor del indicador, aspecto que sugiere que su precio en relación a su IASPB es prudente si se compara con las zonas restantes. No es así el caso de la zona O-9, que supera el valor de la O-1, pese a ser más distante del centro urbano. Sin embargo, ambas zonas mantienen valores del indicador relativamente inferiores, ya que su precio guarda correspondencia con el modelo de valorización de cono invertido, típico en las ciudades mono céntricas.

6 Por cada indicador se plantea una ficha metodológica que permite homologar y estandarizar los datos obtenidos para cada indicador. 
FIGURA 3. INCREMENTO DEL PRECIO DEL SUELO URBANO EN BASE A LA INFORMACIÓN DE LA OFERTA.

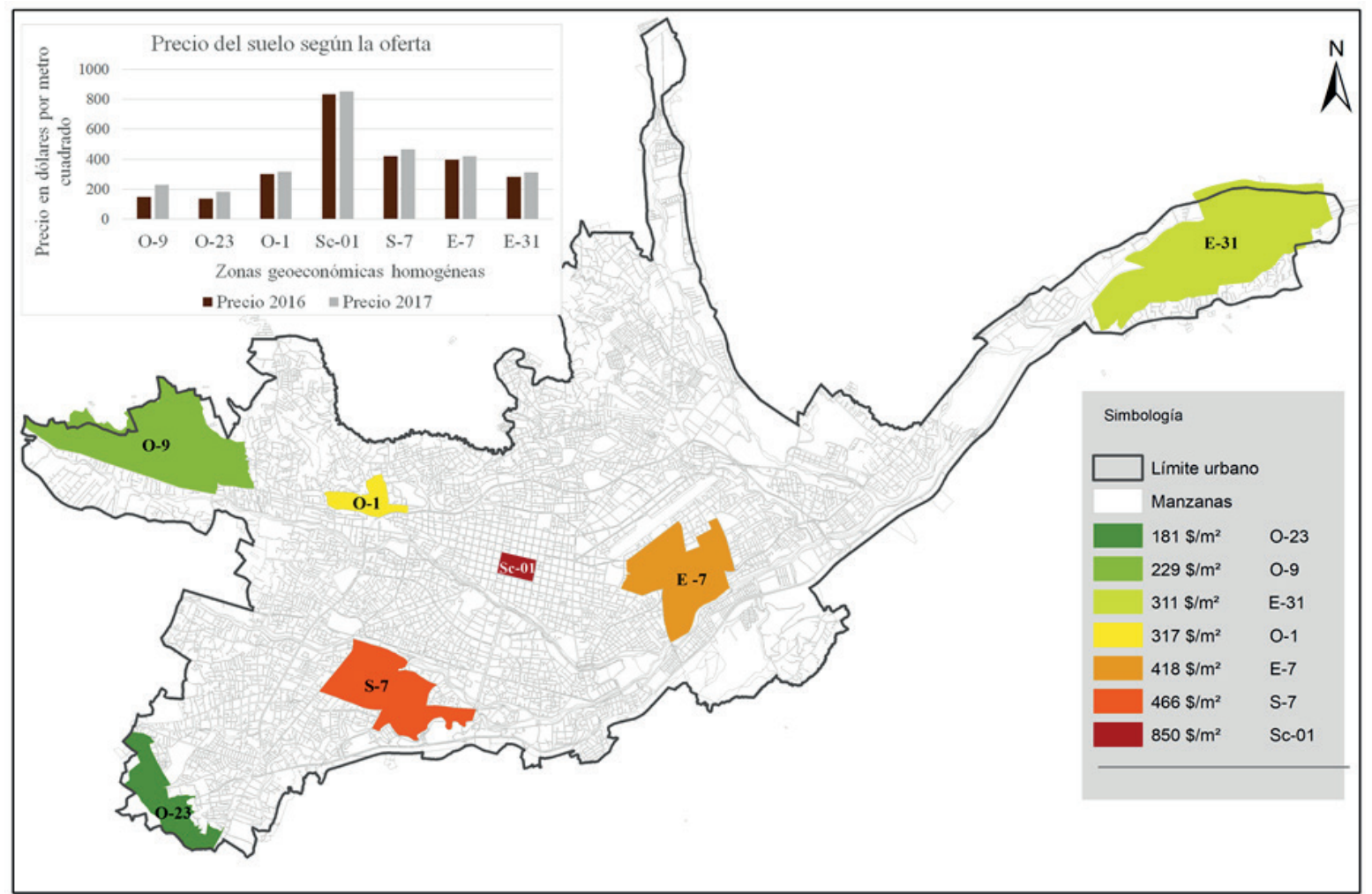

Fuente: Autores (2019). 
FIGURA 4. RELACIÓN DEL PRECIO SUELO CON EL ÍNDICE DE ACCESO A SERVICIOS BÁSICOS PÚBLICOS Y PORCENTAJE DE OCUPACIÓN DEL SUELO URBANO.
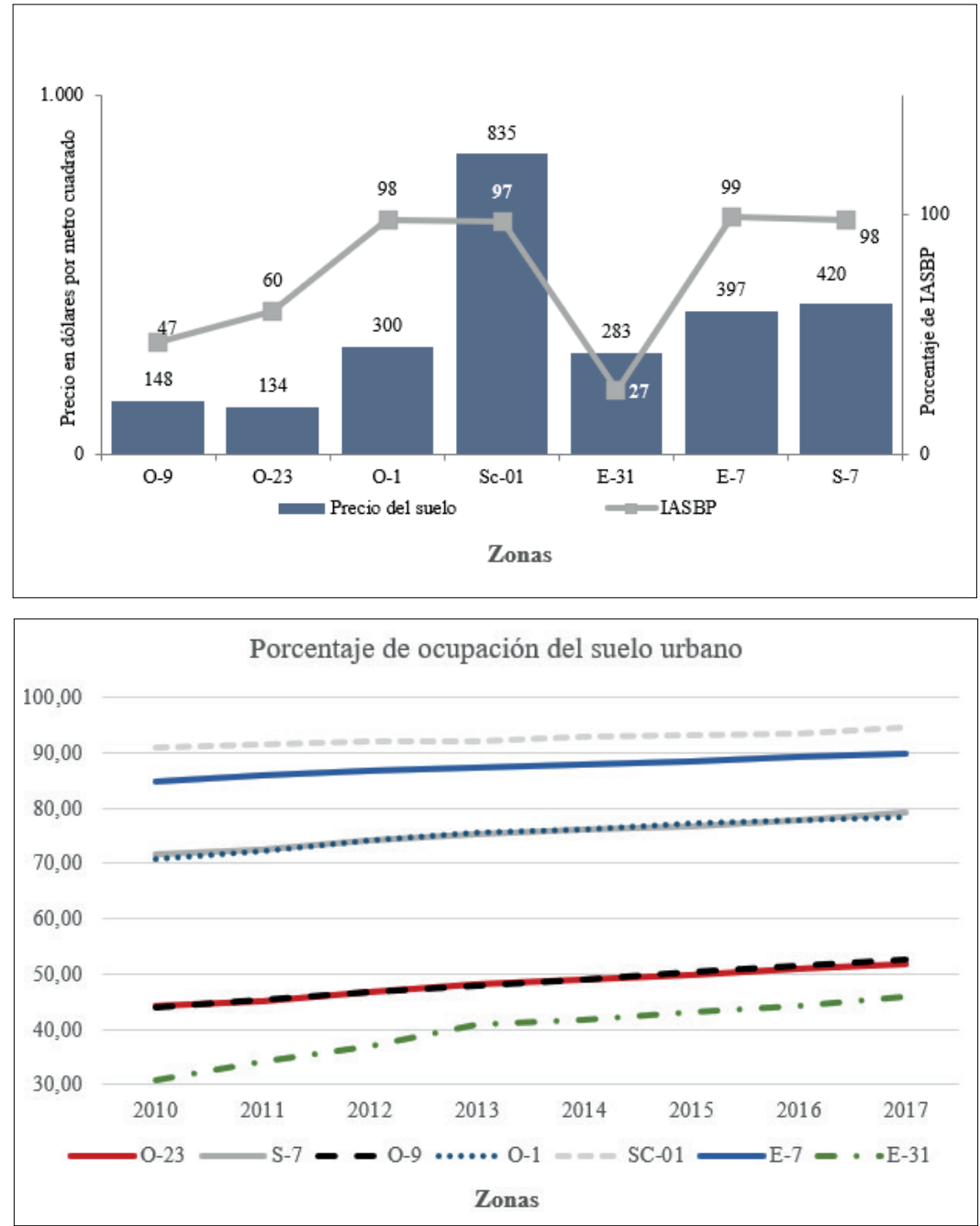

Fuente: Autores, 2019. 
FIGURA 5. PLANO DE PENDIENTES Y COBERTURA DE TRANSPORTE PÚBLICO, ÁREA URBANA DE CUENCA.

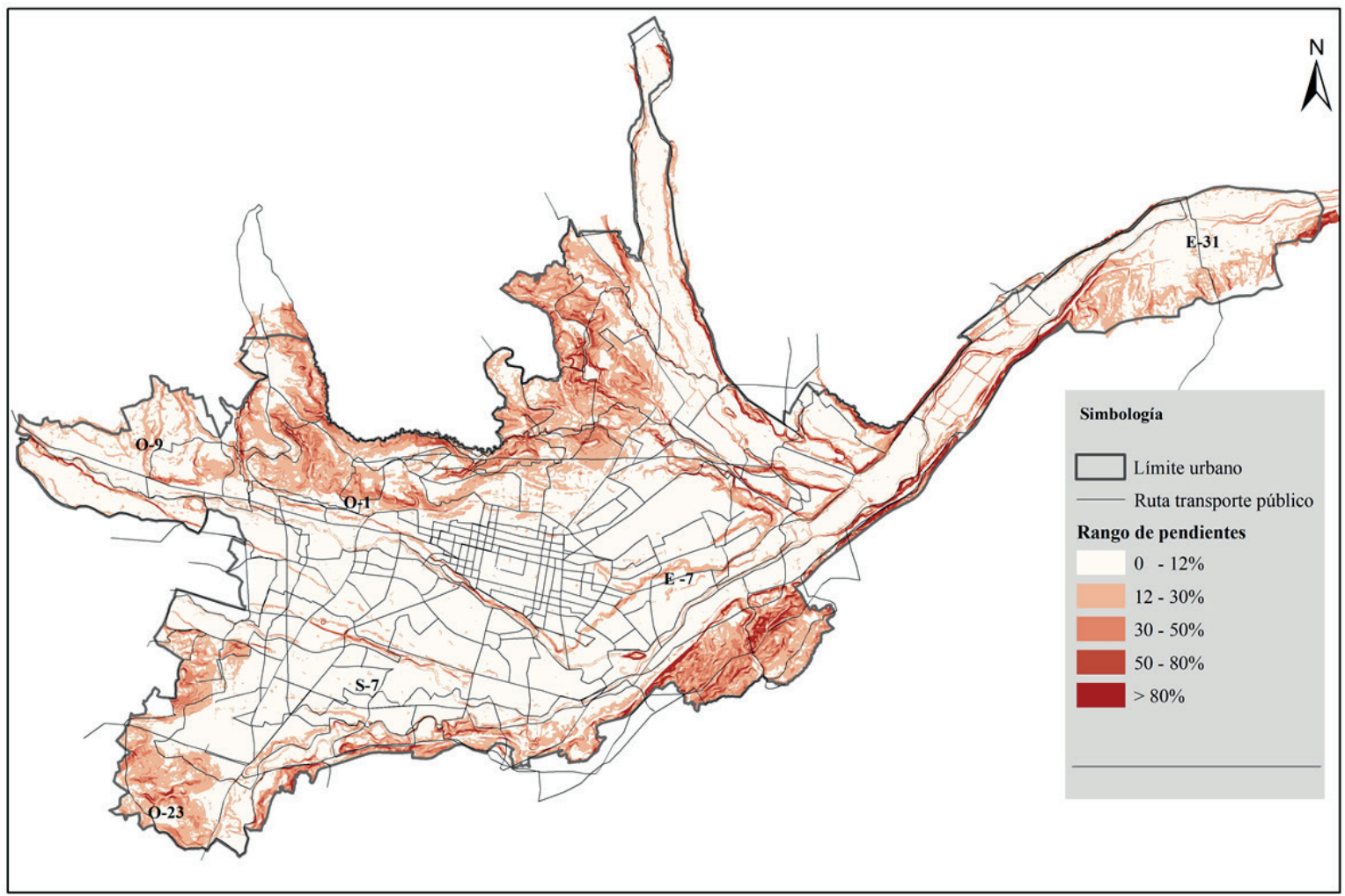

Fuente: Autores, 2019. 
La Figura 5, muestra las rutas de transporte público y un plano de pendientes del área urbana de Cuenca. En ella, se observa que las zonas E-31, O-9 y O-23 no cuentan con el mismo grado de cobertura de transporte público que el resto de zonas, ya que en la E-31 se pueden identificar distancias de hasta $1.5 \mathrm{~km}$ hasta la línea de ruta. En la zona O-23, el precio está por debajo de la O-9; esto se debería, a que la primera presenta pendientes superiores al 30\%, lo cual reduciría su valor debido a que los costos de edificación son mayores en pendientes pronunciadas.

b) En relación a la extracción de suelo urbanizado de la esfera de circulación

Hasta el momento no es posible justificar los precios que alcanzan las zonas O-9 y E-31, debido a su elevado valor por sobre su bajo índice de servicios y a su distancia del centro urbano. La figura 5 evidencia que en el período 2010 a 2017 las zonas O-9 y E-31 son las que presentan los mayores incrementos de ocupación (20 y 49\% respectivamente), hecho que permite advertir que el incremento en el precio del suelo de la zona O-9, por sobre el resto de zonas para el año 2017, sería un suceso que se manifestaría a partir de la aceleración en el grado de ocupación, ya que "si la demanda por espacio urbano aumenta y la cantidad de tierra permanece fija, el precio debe subir debido fundamentalmente a la agudización de la escasez", (Jaramillo, 2014, p.
14). Este fenómeno parece sustentarse en zonas como la E-7 y Sc-01, donde el porcentaje de ocupación crece en valores relativamente bajos (5,97 y 4,11\% respectivamente), fomentando valorizaciones de menor grado.

c) En relación al impacto de los excedentes especulativos en el acceso a la propiedad de suelo bien servido

En base a la comparación de los valores que reflejan cada una de las zonas de los diferentes indicadores, se evidencia que algunas zonas periféricas presentan valores relativamente altos en relación con los mostrados en las zonas céntricas. Un aspecto esencial en la tarea de establecer crecimiento injustificado del precio del suelo es poder contrastar el precio con el "trabajo social invertido en el suelo (inversión en atributos que mejoran las condiciones del suelo para los usos urbanos)" (Guamán, 2018, p. 142). La carencia de información constituye una limitante para este fin, sin embargo, esto se puede estimar contrastando el incremento del precio del suelo con el de otras mercancías. Tal incremento se debe al resultado de un proceso inflacionario que afectaría a las mercancías en general, incluyendo a aquellas ligadas a la producción de suelo urbano (materiales para infraestructura de vías, de servicios, adecuación topográfica para la edificación). Por lo tanto, el indicador Relación precio suelo - salario básico unificado permite establecer la disparidad entre el crecimiento de otras mercancías (por ejemplo, los insumos de la canasta básica familiar - IPC). 
FIGURA 6. INCREMENTO DEL PRECIO DEL SUELO EN CUENCA Y DEL SBU.

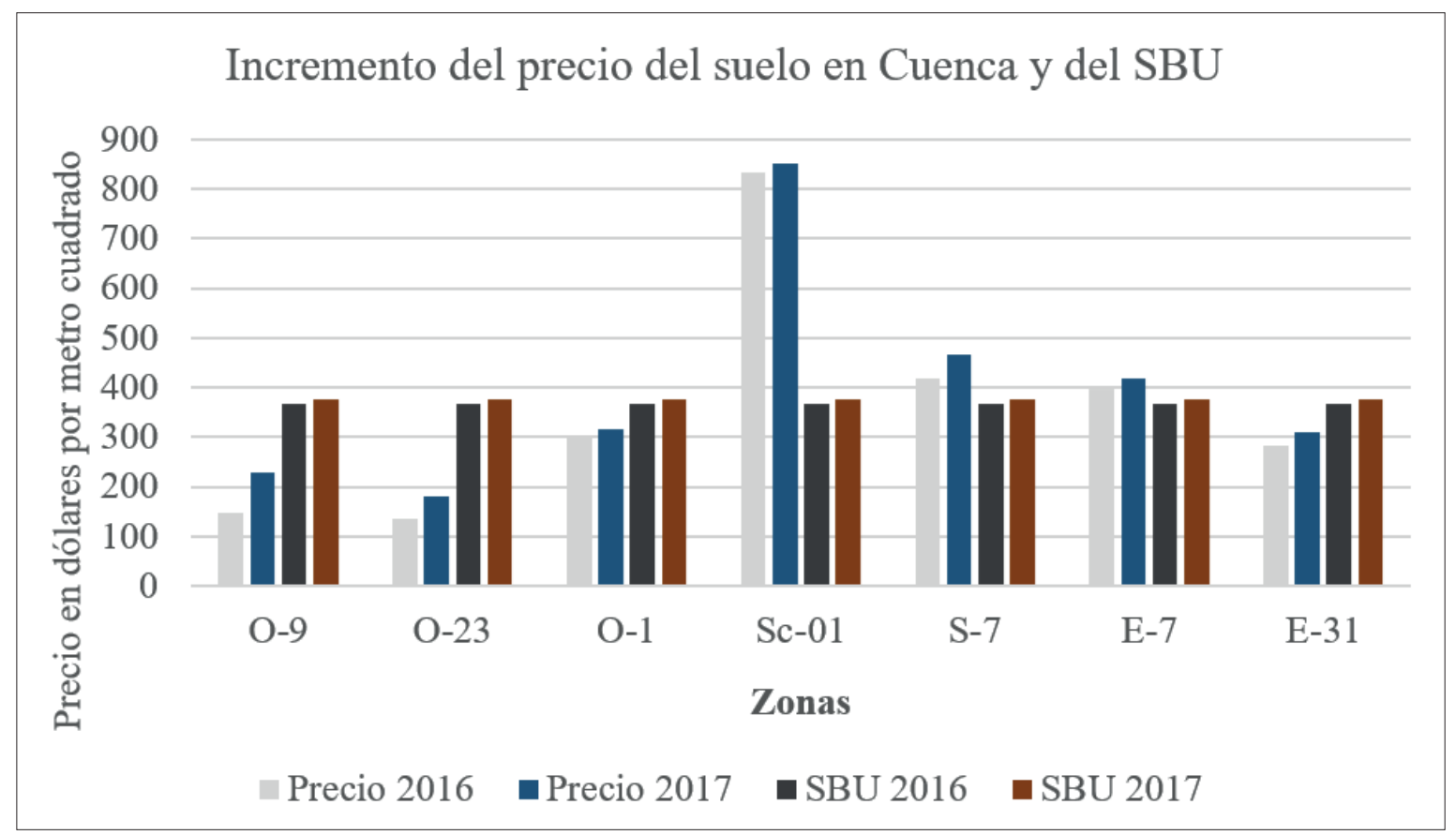

Fuente: Autores, 2019. 
En la Figura 6, el valor que alcanza el indicador del sector Sc-01, se mantiene como el mayor en los dos años, un resultado esperado debido a que, según la lógica del indicador, los precios del suelo más altos presentarán mayor disparidad con el SBU. La figura 6, evidencia que este se incrementa en nueve dólares al 2017, en tanto que el precio de la zona O-9 lo hace en 80 dólares, desatándose una disparidad en el movimiento del SBU con respecto al precio del suelo. Ello implica que, para acceder a la propiedad de un metro cuadrado en esa zona, una familia requiere de 0,4 SBU $(146,4 \$)$ en 2016; y 0,6 SBU (225\$) en 2017.

Según la Figura 6, el movimiento del precio en las zonas analizadas es diferenciado, un aspecto que no se puede explicar únicamente a través de las variables planteadas sino que también como el resultado de la influencia de otras externalidades; por ejemplo: la inversión privada o pública a través de la introducción de infraestructura. Como el caso de la zona S-7, que muestra el segundo mayor valor en el incremento del precio, explicable por la edificación de un equipamiento destinado al uso del Registro de la Propiedad del cantón Cuenca. Así mismo en la zona O-9, donde se experimenta el mayor incremento, se debería a que, a partir de 2016, se extendió una avenida. En este caso particular, el excesivo incremento se debería a que la prolongación de la vía facilitaría procesos de fraccionamiento del suelo en lotes de menor superficie, lo que contribuiría a su incremento, pues "a mayor tamaño, menor precio por $\mathrm{m}^{2}$ porque es más difícil venderlo" (Borrero, 2000, p. 67) y viceversa. Este proceso de fraccionamiento, se haría viable debido a que la norma urbanística vigente para esta zona determina que el lote mínimo es de $350 \mathrm{~m}^{2}$, que explicaría la diferencia de valorización con otra zona que se encuentra en un radio similar (la O-23), donde la normativa determina que el lote mínimo (para esta última) es de $1000 \mathrm{~m}^{2}$. Otra zona que experimenta un notable incremento es la zona O-23, lo que habría sido motivado por el emplazamiento de un supermercado de gran concurrencia.

En cuanto a las zonas céntricas (O-1 y Sc-01), el precio del suelo crece en menores valores. Para algunos corredores de bienes raíces de la ciudad, su reducido crecimiento se debe a que la norma urbanística constituye una limitante para la introducción de capital privado, puesto que los permisos para las modificaciones son más complejos, debido a que el centro de Cuenca está declarado como bien patrimonial de la humanidad. La zona central cuenta ya con un alto grado de ocupación (94,56\% en 2017), lo que implica que se dispongan de pocos lotes para la implementación de proyectos con potencial incidencia en la dinámica del mercado de la zona.

Como ha se visto, los valores del suelo presentados podrían no justificarse sólo por los atributos que constituyen su valor de uso social; lo que conlleva el plantearse la posibilidad de que sus valores se sustentan en su potencial 
FIGURA 7. POTENCIAL EDIFICATORIO Y PRECIO DEL SUELO.

\begin{tabular}{|c|c|c|c|c|c|c|c|}
\hline SECTOR & $0-9$ & O-23 & O-1 & SC-01 & S-7 & E-7 & E-31 \\
\hline Precio en $2016\left(\$ / \mathrm{m}^{2}\right)$ & 147,69 & 134,27 & 300,21 & 834,5 & 419,52 & 396,72 & 282,88 \\
\hline Precio en $2017\left(\$ / m^{2}\right)$ & 228,49 & 180,5 & 316,51 & 850 & 465,66 & 418,08 & 310,7 \\
\hline $\begin{array}{l}\text { Max. Pisos permitido } \\
\text { (N. pisos) }\end{array}$ & 12 & 2 & 6 & 3 & 9 & 6 & 2 \\
\hline COS máximo & 0,7 & 0,8 & 0,75 & 0,5 & 0,7 & 0,75 & 0,3 \\
\hline Uso principal & Vivienda & Vivienda & Vivienda & Gestión y administración & Vivienda & Vivienda & Vivienda \\
\hline $\begin{array}{l}\text { Lote aprovechable } \\
\text { máximo }\left(\mathrm{m}^{2}\right)\end{array}$ & 1200 & 1000 & 500 & 300 & 900 & 500 & 750 \\
\hline $\begin{array}{l}\text { Potencial volumen } \\
\text { edificatorio }\left(\mathrm{m}^{2}\right)\end{array}$ & 10080 & 1600 & 2250 & 450 & 5670 & 2250 & 450 \\
\hline
\end{tabular}

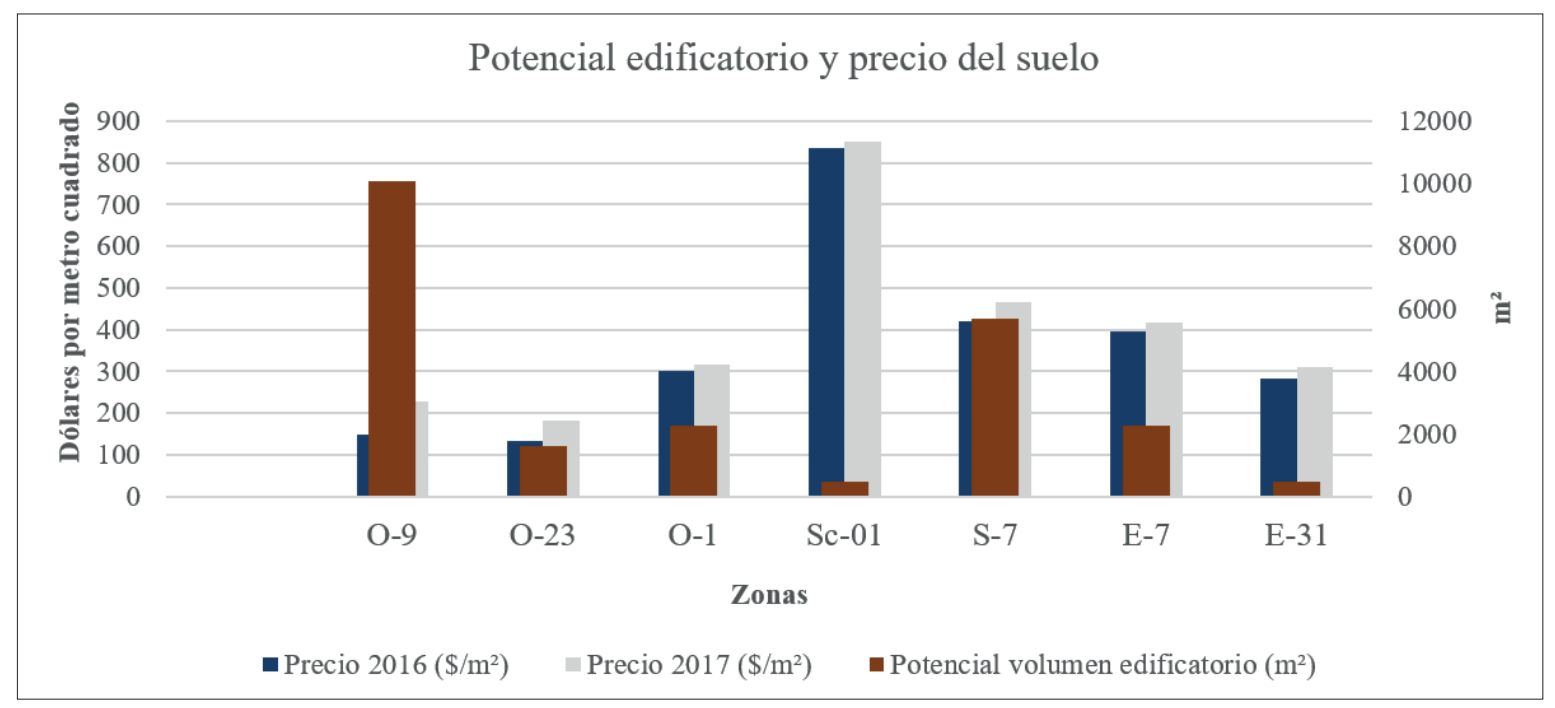

Fuente: Autores, 2019. 
FIGURA 8. PLANO DE POBREZA POR NECESIDADES BÁSICAS INSATISFECHAS DE CUENCA.

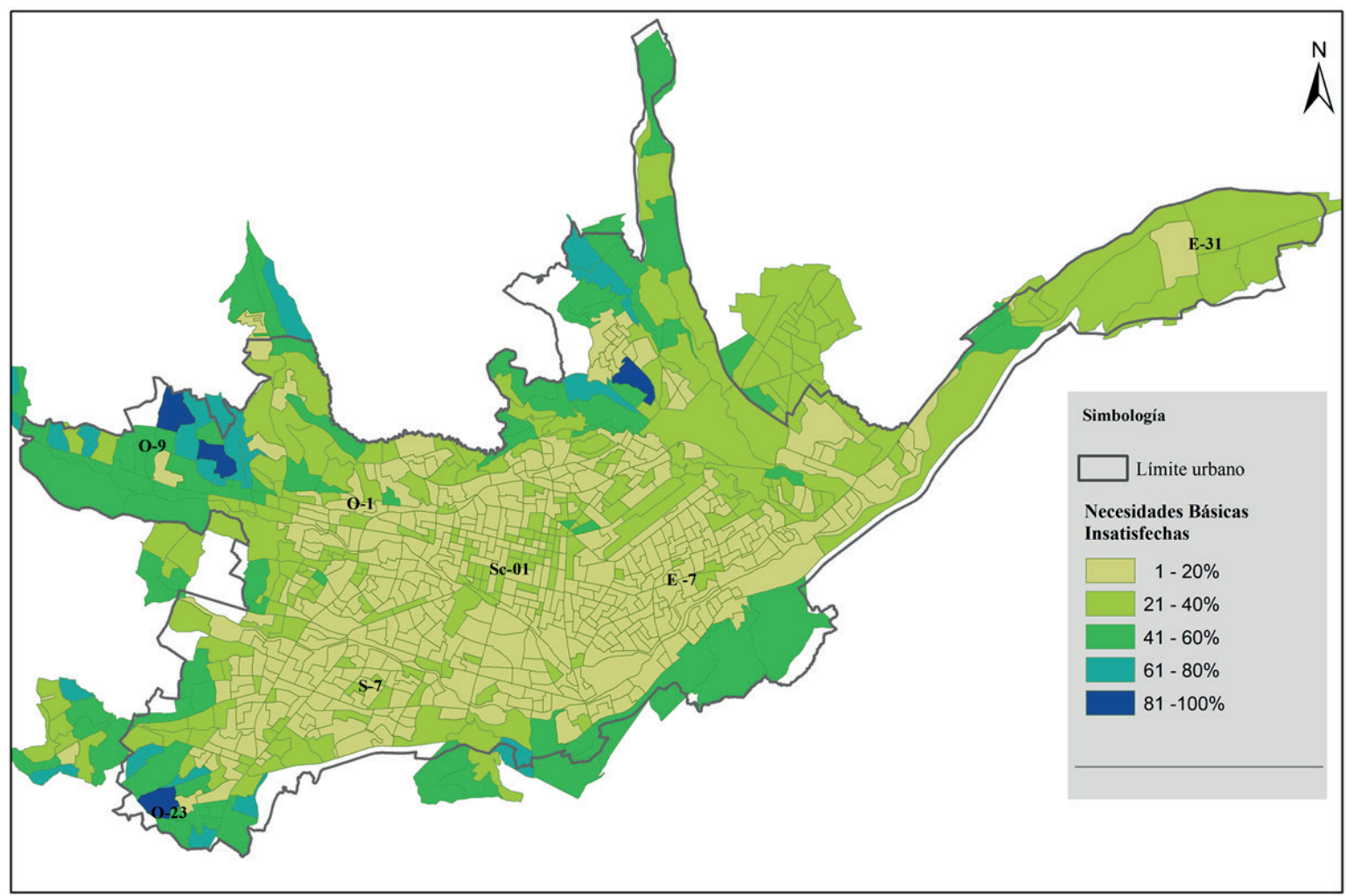

Fuente: Censo de Población y Vivienda (2010), INEC (2010), Autores (2019). 
de desarrollo. Esto es, que sus determinantes urbanísticas condicionen positivamente la "fertilidad" del suelo urbano, es decir logrando que permita un alto índice edificatorio; esto implicaría que se consienta ocupar mayormente el lote y un elevado número de pisos. La mayor edificabilidad permitida determinará que el demandante pague un elevado precio por el suelo; por el contrario, si éste tiene baja edificabilidad, su precio será reducido (Borrero, 2000, p. 130). Así mismo, este aprovechamiento está determinado por el uso permitido en la zona y el estrato social asentado.

En cuanto al uso del suelo, todas las zonas tienen como uso principal la vivienda, a diferencia del sector central (Figura 7). En este sentido, solo Sc-01 evidencia una ventaja sobre el resto de las zonas, en términos de rentabilidad por el uso permitido. La misma figura, muestra que la zona con mayor potencial edificatorio es la O-9; en el otro polo, se encuentra la E-31 con el menor volumen. Pese a que la zona O-9 tiene mejores condiciones para el aprovechamiento edificatorio que la E-31, esta última presenta valores de mercado similares a la O-9. Esto se debería, no solo a que el potencial de desarrollo se basa en las óptimas condiciones para la edificabilidad, sino que además se debe a un factor de demanda y de estatus económico. Tal efecto se puede ver también en las zonas S-7 y E-7, las cuales, pese a que presentan diferentes índices de edificación respecto a lo permitido y se hallan en valores de mercado similares.
Según la Figura 8, los niveles más bajos de pobreza se presentan en las zonas centrales y en la zona E-31, que está dentro del rango de $21-40 \%$. Esto permite estimar el estrato de la población asentada en las diferentes zonas. Considerando que la zona O-9 y la E-31 son las que mayor porcentaje de ocupación presentan, pero que hay una diferencia sustancial con respecto a la población asentada en las dos zonas, se puede decir que la elevada valorización de la zona E-31 -por sobre la O-9 (NBI entre el 61 y 100\%), se debe a que en ella se asienta una población de elevados ingresos económicos. Constituyendo un lugar de "prestigio", en el que el filtro es el elevado valor de cambio del suelo. Esto, en la teoría de las rentas urbanas, se denomina renta de monopolio de segregación.

Es prudente dejar en claro que el extendido lote mínimo de la zona E-31, así como su bajo índice de edificación permitido, se deben a que el comportamiento mecánico de su suelo no soporta grandes volúmenes edificados. Es por ello que, con sus determinantes, lo que se busca es un bajo porcentaje de ocupación en la zona.

El elevado valor solicitado por metro cuadrado para la adquisición de suelo en la periferia no es el único conflicto en el acceso al suelo urbano; además, la norma urbanística vigente para la ciudad de Cuenca (2003) establece que el lote mínimo para las zonas periféricas, como la E-31 y la O-23, es de $750 \mathrm{~m}^{2}$ y $1000 \mathrm{~m}^{2}$ respectivamente, por lo que es necesario invertir cantidades elevadas de dinero para su compra. 
FIGURA 9. AÑOS REQUERIDOS PARA ADQUIRIR SUELO EN EL ÁREA URBANA DE CUENCA.

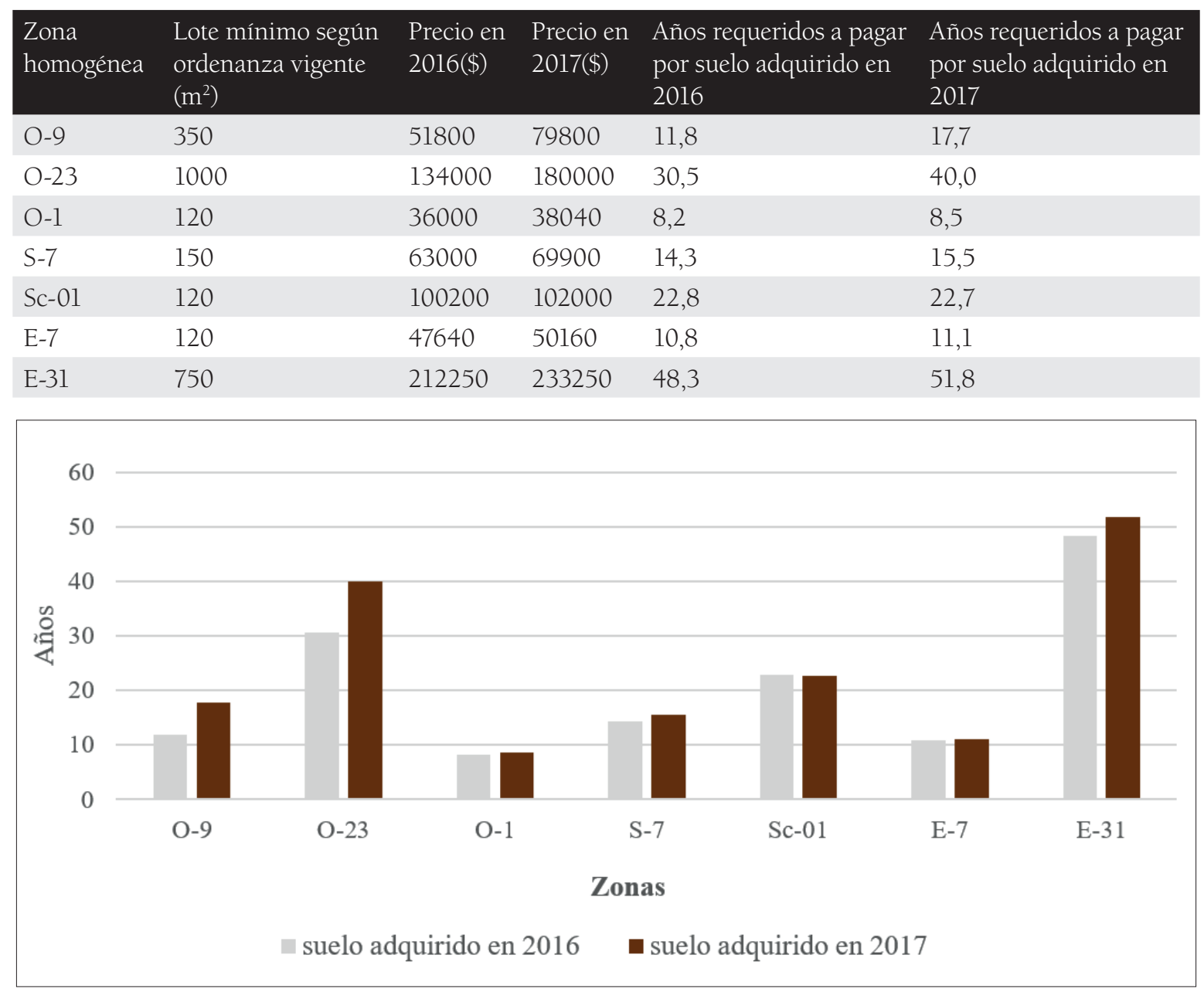

Fuente: Autores, (2019). 
La siguiente figura representa la cantidad de años requeridos para que las familias con una capacidad de pago mensual de un SBU puedan adquirir un lote mínimo en cada zona estudiada ${ }^{7}$.

La Figura 9 denota que para las zonas $\mathrm{O}-23$ y E-31se requiere de una mayor cantidad de años para pagar por un lote mínimo, incluso por sobre las zonas centrales. Ello se debe a su elevado precio y a la extensión de su superficie (que es mayor que en el centro). Este fenómeno muestra que las zonas analizadas ubicadas en la periferia tampoco están al alcance de los sectores con reducida capacidad adquisitiva. Hecho que se replica en otras zonas periféricas de la ciudad, como la Av. Ordoñez Laso y el sector El Ejido, donde en 2016 se podía intercambiar suelo en las vías principales por 600 y 900 dólares por metro cuadrado, en tanto que en las calles internas su precio fluctuaba entre 400 y 800 dólares.

\section{Conclusiones}

Los recargos sobre los lotes ociosos parecen no haber coadyuvado a la ocupación de las zonas centrales. Por el contrario, los mayores valores de incremento de ocupación se registran en la periferia, hecho que contribuye a la expansión geográfica, con bajos valores de densificación, de la ciudad de Cuenca. Además, el efecto valorizador de la periferia, derivado de su ocupación, presiona también el alza del precio en las zonas céntricas, ya que el precio del suelo se configura sobre el terreno marginal. Ahora, si bien el marco legislativo ecuatoriano contempla el gravamen a los lotes ociosos como medida de regulación del mercado de suelo, es importante entender que la movilización de suelo únicamente aplaca la renta que menos presencia tiene en los excedentes especulativos (renta absoluta urbana). En este sentido, el efecto es contraproducente, pues como se evidenció en esta investigación, la aceleración en el movimiento de los bienes inmuebles guarda relación con su valorización, entonces, con el gravamen, el suelo es edificado pero es más caro. Es decir, que se edifique no garantiza que ante el incremento de la oferta se reduzca el precio, lo que hace aún más inaccesible el suelo urbano para las familias pobres. Es por ello que este tipo de normativa debe funcionar simultáneamente con otros instrumentos que garanticen la generación de vivienda social.

El caso de Challuabamba (zona E-31), que muestra precios elevados en relación a los bajos niveles de servicios existentes en la zona y su bajo potencial edificatorio, evidencia que su valorización se sustenta en una renta de

$7 \quad$ El cálculo no considera el excedente que se deriva del tipo de interés de los créditos para la adquisición de vivienda. 
monopolio de segregación que, en este caso, es aún más fuerte que las potenciales utilidades de la edificación intensiva de Rio Amarillo (zona O-9); también en esta zona, junto con Narancay (O-23), el precio experimenta incrementos desmesurados en el período 2016-2017, sin presentar mejoras en los condiciones del suelo para su valor de uso social, atribuyéndoseles valores fundamentados en las rentas urbanas.

En consecuencia, el suelo al que pueden acceder las familias pobres -ingresos monetarios por menos de dos SBU (Instituto Nacional de Estadística y Censos, 2012)- en Cuenca se ha emplazado cada vez más lejos de las zonas privilegiadas, realizándose la materialización del acceso a la ciudad para los pobres mediante la informalidad, debido a la evidente debilidad que han mostrado las políticas públicas en el mercado de suelo en Ecuador. Además, las introducidas únicamente inciden cuando interviene el Estado en busca de generación de vivienda social. Este aspecto se complejiza al haber una débil recaudación de impuestos sobre la tierra; al no considerar las alianzas público-privada, y al no contar con herramientas fuertes de captura de plusvalías para el financiamiento del desarrollo urbano. Los hallazgos de este estudio sugieren que la Ley de Plusvalías se constituyó en una potencialidad para la mejora en la recaudación tributaria y la captura de excedentes especulativos para el financiamiento de vivienda social. No obstante, su derogatoria fue el resultado de los argumentos sin sustento de algunos grupos económicamente dominantes, quienes sostenían que la Ley afectó al negocio inmobiliario y a la oportunidad de inversión en este mercado.

\section{Referencias bibliográficas}

Acosta, C. (2019). Regulaciones de suelo, infraestructuras y soportes urbanos, y vivienda social en debates de derecho comparado. En Manual de derecho urbano. Bogotá: Editorial Universidad del Rosario.

Baer, L. y Kauw, M. (2016). Mercado inmobiliario y acceso a la vivienda formal en la Ciudad de Buenos Aires, y su contexto metropolitano, entre 2003 y 2013. EURE, 42(126), 7-12. https://doi.org/10.4067/S0250-71612016000200001

Bagnera, P. (2016). El derecho a la ciudad en la producción del suelo urbano. Serie Estudios sobre la pobreza y las desigualdades. Buenos Aires: CLACSO.

Banco Central del Ecuador. (s.f.). Cuentas nacionales regionales. Recuperado de

https://contenido.bce.fin.ec/documentos/ Estadisticas/SectorReal/CuentasCantonales/Indice. htm

Borrero, 0. (2000). Factores y métodos para el avalúo comercial. Avalúo de inmuebles y garantías. Bogotá: Bhandar Editores.

Camargo, A. y Hurtado, A. (2013). Urbanización informal en Bogotá: agentes y lógicas de producción del espacio urbano. Revista INVI, 28(78), 77-107.

https://doi.org/10.4067/S0718-83582013000200003 
Cesare, C. (1998). Uso del impuesto a la propiedad para recuperar plusvalías: estudio de un caso práctico en Brasil. En M. Smolka y L. Mullahy (Eds.), Perspectivas urbanas: temas críticos en politicas de suelo en América Latina (193-176). Cambridge, Estados Unidos.

Código orgánico de organización territorial, autonomía y descentralización, Ecuador, 19 de octubre de 2010.

Constitución de la República del Ecuador. (2008, 20 de octubre). Registro oficial nro. 653.

Espasa, L. C., Fittipaldi, R. A., y Michalijos, P. (2010). El mercado de suelo urbano y su incidencia en la configuración urbana. Estudio de caso: ciudad de Monte Hermoso. Huellas, (14), 163-182.

Gonzáles, L. (2016). La renta del suelo y sus efectos sobre los precios de los terrenos residenciales en Bogotá (tesis de pregrado). Escuela Colombiana de Ingeniería Julio Garavito.

Guamán, V. (2018). Diseño conceptual de proyecto piloto de observatorio de precios de suelo en Ecuador (Tesis, Universidad de Cuenca, Cuenca). Recuperado de http://dspace.ucuenca.edu.ec/handle/123456789/31706

Harvey, D. (2014). Diecisiete contradicciones y el fin del capitalismo. Quito: Instituto de Altos Estudios Nacionales.

Instituto Nacional de Estadística y Censos. (2012). Encuesta nacional de ingresos y gastos de los hogares urbanos y rurales 2011- 2012. Quito: Autor.
Jaramillo, S. (2014). Dinámica de los precios del suelo urbano en Bogotá 1970-2012. Bogotá: Universidad de los Andes-Facultad de Economía-CEDE.

Jaramillo, S., Moncayo, V., y Alfonso, 0. (2011). Plusvalias urbanas. Fundamentos económicos y jurídicos. Bogotá: Universidad Externado de Colombia, Facultad de Economía.

Ley orgánica de ordenamiento territorial, uso y gestión de suelo, Ecuador, 30 de junio de 2016.

Ley orgánica para evitar la especulación sobre el valor de las tierras y fijación de tributos, Ecuador, 29 de diciembre de 2016.

Martín, A. y Camas, A. (2017). Regulación y mercado de suelo en España. Presupuestos para el debate. EURE, 43(130), 141-160.

https://doi.org/10.4067/s0250-71612017000300141

Molinatti, C. (2013). Financiamiento urbano a través de la movilización de plusvalías. En D. Erba (Org.), Definición de políticas de suelo urbano en América Latina: teoría y práctica (pp. 133-150). Cambridge, MA: Lincoln Institute of Land Policy.

Municipalidad de Cuenca. (s.f.). Reforma, actualización, complementación y codificación de la ordenanza que sanciona el plan de ordenamiento territorial del Cantón Cuenca: determinaciones para el uso y ocupación del suelo urbano. Recuperado de https://www.slideshare.net/conejitavas/ ordenanza-cuenca 
Reyes, F. y Tubío Sánchez, J. (2018). Reflexiones del efecto de la plusvalía sobre la oportunidad de acceso a la tierra. Red de Investigación en Gestión del Territorio. Recuperado de https://planoss.github.io/conferenciarigtig/page3. html\#headerl-k

Smolka, M. (2003). Informalidad, pobreza urbana y precios de la tierra. En M. Smolka y L. Mullahy (Eds.), Perspectivas urbanas: temas críticos en políticas de suelo en América Latina (pp. 71-78). Cambridge, MA: Lincoln Institute of Land Policy.

Smolka, M. (2014). Implementación de la recuperación de plusvalías en América Latina. Políticas $e$ instrumentos para el desarrollo urbano. Cambridge, MA: Lincoln Institute of Land Policy

Urriza, G. (2006). Efectos del mercado de suelo y los precios en el desarrollo urbano de Bahía Blanca. Revista Universitaria de Geografía, 15(1). 


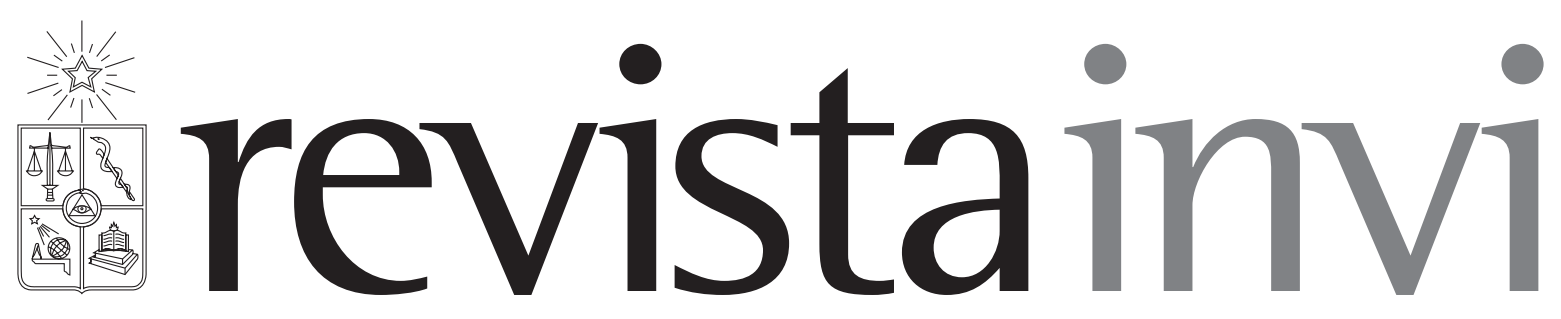

Revista INVI es una publicación periódica, editada por el Instituto de la Vivienda de la Facultad de Arquitectura y Urbanismo de la Universidad de Chile, creada en 1986 con el nombre de Boletín INVI. Es una revista académica con cobertura internacional que difunde los avances en el conocimiento sobre la vivienda, el hábitat residencial, los modos de vida y los estudios territoriales. Revista INVI publica contribuciones originales en español, inglés y portugués, privilegiando aquellas que proponen enfoques inter y multidisciplinares y que son resultado de investigaciones con financiamiento y patrocinio institucional. Se busca, con ello, contribuir al desarrollo del conocimiento científico sobre la vivienda, el hábitat y el territorio y aportar al debate público con publicaciones del más alto nivel académico.

Director: Dr. Ricardo Tapia Zarricueta, Universidad de Chile, Chile.

Editor: Dr. Luis Campos Medina, Universidad de Chile, Chile.

Editor asistente: Dr. Walter Imilan, Universidad de Chile, Chile.

Coeditora: Srta. Sandra Rivera, Universidad de Chile, Chile.

\section{COMITÉ EDITORIAL:}

Dr. Victor Delgadillo, Universidad Autónoma de la Ciudad de México, México.

Dra. María Mercedes Di Virgilio, CONICET/ IIGG, Universidad de Buenos Aires, Argentina.

Dra. Irene Molina, Uppsala Universitet, Suecia.

Dr. Gonzalo Lautaro Ojeda Ledesma, Universidad de Valparaíso, Chile.

Dra. Suzana Pasternak, Universidade de São Paulo, Brasil.

Dr. Javier Ruiz Sánchez, Universidad Politécnica de Madrid, España.

Dra. Elke Schlack Fuhrmann, Pontificia Universidad Católica de Chile, Chile.

Dr. Carlos Alberto Torres Tovar, Universidad Nacional de Colombia, Colombia.

Sitio web: http://www.revistainvi.uchile.cl/

Correo electrónico: revistainvi@uchilefau.cl

Licencia de este artículo: Creative Commons Atribución-Compartirlgual 4.0 Internacional (CC BY-SA 4.0) 